\section{Suspected poisoning in childhood} Sir,

All new information on the problem of ingestion of poisons in childhood is valuable. However, it would be damaging if a sense of complacency were engendered by the work of Calnan, Dale, and de Fonseka (1976). It is undisputed by anyone who has worked in this field that the majority of children coming into hospital come to no harm, and in retrospect the incidents seem to be trivial. However, it would be dangerous to assume that these children are aetiologically different from those who suffer serious side effects from ingesting poisons. The child who takes his grandmother's antibiotics is no different, aetiologically speaking, from a child who takes his grandmother's digoxin. However, one would be classified by Calnan as a poisoning scare and the other as a true poisoning.

There must be doubt also about the method of Calnan et al. of classifying their 'poisoning scares' and 'true poisonings'. It is the aim of treatment to empty the stomach as soon as possible to prevent symptoms. How many of Calnan's children would have developed symptoms had the stomach remained unemptied? The majority of children's departments throughout the United Kingdom now use Ipecacuanha emesis. This is an effective and humane method of emptying the stomach (Boxer, Anderson, and Rowe, 1969), and its use prevents many of the problems of hospital admission that Calnan and his colleagues fear.

There is one commonly taken poison for which blood levels are easily available. This is aspirin. The vast majority of children who present to casualty after aspirin ingestion have detectable salicylate in their blood, which suggests that children are not commonly presented to casualty with a suspicion of taking poisons who have in fact not taken the poison at all. If children who have probably not taken sufficient amounts of poison are sent home there will occasionally be disasters. I can do no better than quote from the report of Medical Defence Union in 1975 where the death of a child from aspirin poisoning is described. He had been sent home from hospital having been thought to have taken insignificant amounts of junior aspirin. The Medical Defence Union emphasized the importance of admitting all such children to hospital. It has been shown that stress is an important factor in the aetiology of ingestion of poisons in childhood (Sibert, 1975; Julyan and Kuzemko, 1975). Parents may not be able to give accurate information at such times. When the work of Calnan, Dale, and de Fonseka was published previously (Calnan, 1974) in the correspondence which followed in the British Medical Journal, de Fonseka (1975) said that even very anxious mothers can be adequately questioned when first seen, and can provide very reliable information. I believe this not always to be the case.

In addition, there may always be the possibility of nonaccidental poisoning (Rogers et al., 1976). The diagnosis here seems always to be difficult and would be almost impossible to make if the children were sent home. Accidental child poisoning may be a symptom of a variety of family problems. It is usually impossible to find out about these and to alert the appropriate agency if the child is not admitted to hospital.

It may be that in time, with the improvement of liaison between general practice, the community services, and the hospital, children who have ingested poisons will be sent home for adequate observation. However, at the present time safety demands the majority of children should be admitted to hospital.

\section{J. R. SIBERT \\ Department of Child Health, Welsh National School of Medicine, Heath Park, Cardiff CF4 $1 X N$.}

\section{REFERENCES}

Boxer, L., Anderson, F. P., and Rowe, D. S. (1969). Comparison of ipecac-induced emesis with gastic lavage in the treatment of acute salicylate ingestion. Fournal of Pediatrics, 74, 800.

Calnan, M. W. (1974). Accidental child poisoning. Community Health, 6, 91 .

Calnan, M. W., Dale, J. W., and de Fonseka, C. P. (1976). Suspected poisoning in children. Archives of Disease in Childhood, 51, 180.

de Fonseka, C. P. (1975). Poisoning in childhood. British Medical fournal, $1,512$.

Julyan, M., and Kuzemko, J. A. (1975). Accidental poisoning in children: the sick family. Practitioner, 214, 813.

Medical Defence Union (1975). Admit aspirin cases. Annual Report, p. 19. Medical Defence Union, London.

Rogers, D., Tripp, J., Bentovim, A., Robinson, A., Berry, D., and Goulding, R. (1976). Non-accidental poisoning: an extended syndrome of child abuse. British Medical fournal, 1, 793.

Sibert, J. R. (1975). Stress in families of children who have ingested poisons. British Medical fournal, 3, 87.

\section{Dr. J. W. Dale comments as follows:}

Thank you for the opportunity of replying to Dr. Sibert's letter. It was not our intention to introduce a sense of complacency about the number of children brought to hospital each year with suspected poisoning. We wished to distinguish between poisoning scares not requiring treatment and true poisoning that may require active treatment, to avoid the types of death referred to by Dr. Sibert while at the same time not increasing the load on hospital facilities.

The aetiology of a disease is the study of factors which cause the disease; our paper made little reference to 